\title{
Economic Modelling of Energy Services: Rectifying Misspecified Energy Demand Functions
}

\author{
Lester C Hunt ${ }^{a}$ and David L Ryan ${ }^{\text {b,* }}$ \\ ${ }^{\text {a}}$ Surrey Energy Economics Centre (SEEC), School of Economics, University of Surrey, UK. \\ t: +44(0)1483 686956.e: L.Hunt@surrey.ac.uk \\ ${ }^{\mathrm{b}}$ Department of Economics, University of Alberta, Edmonton AB Canada T6G 2H4. \\ t: (+1) 780 492-5942.e: David.Ryan@ualberta.ca
}

\section{Introduction}

Energy practitioners often emphasize that energy is desired not for its own sake, but for the services that it produces, such as space and water heating, cooling, lighting, cooking, etc. Nevertheless, especially in empirical energy demand work, this feature appears to be frequently overlooked, as researchers tend to focus on modelling demand for aggregate energy, or for particular energy sources, such as natural gas, electricity, and oil products (see, for example, Bentzen and Engsted, 1993; Huntington, 2010). However, as we demonstrate in this paper, there are potentially important, and in many cases useful, implications that arise from explicit consideration of energy as a derived demand, and ignoring such consideration results in energy demand models that are typically misspecified and from which resulting empirical estimates are likely to be misleading. Further, we show that accounting for this feature requires only minor modifications to the types of energy demand equations that are typically estimated.

This tendency for empirical studies to focus on energy rather than energy services is likely to be largely data driven, since information is often available on aggregate or even individual consumption of particular energy sources, but it is rarely available at either of these two levels on consumption of particular energy services such as heating or lighting. However, as we also demonstrate here, analysis that focuses on demands for energy services can be undertaken even when data on consumption or prices of these services are not readily

\footnotetext{
* Corresponding Author
} 
available. Another contributing factor to the focus on energy rather than energy services could pertain to interest in determining measures of price and income responsiveness (elasticities). Since neither the price nor the quantity consumed of, for example, heating services is generally observed, there might seem to be less interest in the own-price elasticity of demand for heating than in the own-price elasticity of demand for natural gas. Interest in examining the likely effects of various strategies that aimed at reducing dependence on fossil fuels may well reinforce this effect, because mechanisms like carbon taxes or various cap and trade schemes can typically be translated into an effect on the prices of these fuels rather than effects on the prices of energy services. Yet, as we show in this paper, analysis that focuses on energy rather than on energy services might well result in misleading estimates of elasticities, and therefore of the effects that will result from such policies.

In this paper we demonstrate that a more conducive environment for analysis of many aspects of energy economics is provided by returning to the idea that energy is demanded for the services it provides rather than for any intrinsic reasons. To this end, we develop a model of consumer behaviour in which utility is derived from consumption of these services rather than from the energy sources that are used to produce them. A particular advantage of this framework is its demonstration of the direct role for energy efficiency in determining energy demand, even if energy efficiency may be predetermined at the time that current-period energy demand decisions are made. While this formulation yields demand equations for energy services rather than for energy or particular energy sources, we demonstrate that the resulting equations can be readily converted into the standard type of energy demand equation(s) that is (are) typically estimated, although the resulting equations do involve some additional terms. This approach therefore highlights the misspecification that is implicit when typical energy demand equations are estimated, and shows how it can be readily rectified. For empirical purposes, an apparent drawback of this formulation is that 
information is required on energy efficiency, and this is typically not directly observed. In previous work, some authors (such as Beenstock and Willcocks, 1981 and Dimitropoulos et al., 2005) have used a deterministic or a stochastic trend to proxy energy efficiency. Other authors (such as Walker and Wirl, 1993 and Haas and Schipper, 1998) have attempted to construct summary measures of energy efficiency, and in some specific applications, energy efficiency can be observed (see, for example, Schleich et al., 2014). These approaches, implicitly assume that the impact of energy efficiency is exogenous, and neglect the ideas of some authors (such as Kouris, 1983) that energy efficiency (technical progress) should be considered to be endogenous, determined by energy price movements. In contrast, the approach we develop here encompasses both approaches allowing for energy efficiency to be endogenous and thus dependent on past prices as well as other (exogenous) factors.

To summarize, the energy demand equations that we derive from, and which are consistent with, the idea that demand is for energy services rather than energy itself, are no more complex than those that are typically estimated. Yet, they avoid a common misspecification problem without requiring data on variables that are unlikely to be generally available, and allow for the endogeneity of energy efficiency. In addition, the energy services approach opens up the possibility of examining many aspects of energy economics in a way that has not been previously possible.

The remainder of the paper is organized as follows. Section 2 provides background in terms of the few previous papers that have formally considered utility as being derived from energy services rather than energy itself. However, the full implications of this approach and the development of estimating equations that account for all the features described above are not fully considered in this earlier work, which has often been focused more narrowly on trying to capture the irreversibility of energy efficiency improvements. Section 3 introduces a new approach based on a theoretical model of utility maximization conditional on energy 
services. Initially the case of an aggregate energy source and aggregate energy service is considered. This is subsequently extended to the case of multiple energy sources and energy services where each energy source provides only one energy service. Finally, this model is generalized to allow for particular energy sources providing multiple energy services (such as natural gas providing space heating as well as cooking services), and for specific energy services being provided by multiple energy sources (such as space heating being provided by natural gas and/or electricity). Section 4 addresses issues of empirical implementation of the energy services models, while different approaches to modelling unobserved energy efficiency are considered in Section 5. Section 6 provides an empirical illustration, with a brief summary and conclusion presented in Section 7.

\section{Background}

The starting point for our approach is the observation that particular energy sources such as electricity, natural gas, and oil products - are not of intrinsic value to consumers. Rather, energy is used in conjunction with certain types of capital equipment (some of it energy-using, such as furnaces, air conditioners, motors, etc.; and some of it in the nature of a substitute, such as insulation) to provide energy-related services (such as hot or cold air for space heating or cooling, hot water, etc.), and it is these services that are valued by consumers. In this regard, three particular characteristics of energy-using equipment are of relevance: much of it is long-lived - once installed it may have a useful life that spans decades; much of it is fuel(s)-specific; and its technical characteristics tend to be fixed, requiring a given level of energy use per unit of services produced.

There are a variety of factors that may induce consumers to change the stock of energy-using capital (for example by purchasing more energy-efficient appliances) and to substitute capital for energy (for example by installing insulation), such as a sustained period 
of high energy prices. This would also encourage manufacturers to improve the energy efficiency of capital equipment, thereby reducing the quantity of energy needed to produce a given level of energy-related services. In such circumstances, one might also expect governments to act and modify building codes and standards applied to energy-using equipment in directions that encourage greater energy efficiency, for example. Indeed, both of these types of developments were observed in most industrialized countries following the world oil price increases of the 1970 s, and have continued to be observed much more recently, although possibly for different reasons, such as concerns with climate change and a desire to reduce consumption of fossil fuels. Of course, the types of changes described here could also just be the result of the typical processes that give rise to technological progress.

Regardless of what motivates such changes, one way to categorize all these effects is as changes in energy efficiency, that is, the efficiency with which energy is converted into energy services. This efficiency can refer directly to the capital (appliance) that is usedsuch as more efficient furnaces or boilers that use less energy to produce the same amount of heat, or to the installation of supplementary capital, such as attic or wall insulation, or window replacement, or even just sealing of air leaks around windows, that mean that even using the same appliance, less energy is required to produce the same level of thermal comfort or other energy services. In all these cases, the key characteristic is so-called energy efficiency; that is the amount of energy services obtained from a given amount of energy. ${ }^{1}$ And the key problem in terms of understanding the effects of these changes on energy demand is that traditional energy demand models do not usually include explicit measures of energy efficiency, although as mentioned above, some empirical work has included exogenous terms that attempted to proxy technical progress and energy efficiency.

\footnotetext{
${ }^{1}$ Note that this definition is usually associated with appliances associated with households and firms as distinct from the arguments around economy-wide aggregate energy efficiency and energy intensity (see for example, Filippini and Hunt, 2011).
} 
There have been at least two attempts to develop and estimate models of energy demand that take account of the key elements of this discussion involving energy efficiency. Walker and Wirl (1993), in addressing the issue of apparent asymmetry in energy demand for transportation as real (fuel) prices rise and fall, introduce the idea that utility depends on services, where services are the product of energy (fuel) consumption and the efficiency of the equipment (vehicles). Maximization of such a utility function yields the condition that marginal utility equals the price of services, which is equated to the price of energy (gasoline) divided by energy efficiency. The authors construct a series for efficiency based on various technical vehicle characteristics and an assumed depreciation rate, and estimate a services demand function for three countries. Walker and Wirl emphasize the need to measure technological efficiencies and not observed efficiencies, since the latter are affected by numerous vehicle attributes that are reversible. While such an emphasis might be useful for focusing on the irreversibility aspect of technological change, in the context of understanding energy demand this might be viewed as a secondary objective, since any type of increased (or decreased) efficiency, whether technological or observed, will potentially affect such demand. We return to this issue in Section 5.

Apart from this focus purely on particular aspects of energy efficiency, perhaps one of the biggest drawbacks of Walker and Wirl's (1993) approach is that the endogeneity of technical change, that is, of efficiency improvements, such as those induced by real energy price increases, is not explicitly taken into account. The authors do recognize that technical efficiency is dependent on past energy prices and time, and investigate what this relationship might be by constructing an asymmetric filter of past historical energy prices, $Z_{t}$, where $Z_{t}=w p_{t}+(1-w) Z_{t-1}$ if $p_{t} \geq Z_{t-1}$, and $Z_{t}=Z_{t-1}$ otherwise, where $p_{t}$ is the price and $w$ which lies between 0 and 1 , is a weight (smoothing constant). Thus, for example, if $w=1, Z_{t}$ would just be the maximum of the historical sequence of prices, while if $w=0, Z_{t}$ would just 
be the initial price in that sequence. The formulation is designed to account explicitly for the asymmetry of knowledge - that is, that technical knowledge is irreversible - so that $Z_{t}$ cannot decline. Once $Z_{t}$ is constructed, for an assumed value of $w$, Walker and Wirl regress their efficiency measure on $Z_{t-l}$ and find the best fitting combination of $w$ and the lag length, $l$, using a simple inverse functional form. However, this analysis is entirely separate from their services demand function estimation.

Haas and Schipper (1998), who follow a similar type of approach as Walker and Wirl (1993) although focusing on the residential sector rather than road transportation, point out that knowledge of how efficiency changes affect energy demand is important for policy reasons. They consider several approaches to considering the role of irreversible efficiency improvements in affecting energy demand. In one approach they use a bottom-up method, examining particular appliances and particular end uses, to obtain a time series for intensity (energy demand per unit of service, or the inverse of efficiency). This intensity variable is then included as an additional explanatory variable directly in the energy demand equation, and is found to be significant for most countries, although interestingly, with this variable included, the coefficient on price is generally not significant. In another approach they use a lagged value of the filter, $Z_{t}$, of Walker and Wirl (1993), as described above, and include this in the energy demand equation, although it was generally found to be not statistically significant.

Recent theoretical analysis by Goerlich and Wirl (2012) extends the framework of Walker and Wirl (1993) to explicitly include quality as well as services in the utility function. ${ }^{2}$ Although Goerlich and Wirl do not conduct any econometric analysis pertaining to energy demand functions, one of the implications that they draw from their theoretical analysis is that estimates of energy demand elasticities that are obtained from formulations

\footnotetext{
${ }^{2}$ This idea was suggested in a footnote in Walker and Wirl (1993).
} 
that do not account for efficiency - although they again focus just on technical efficiency as defined earlier - will be essentially meaningless, particularly for purposes of policy analysis.

As far as is known, the papers described above are the only studies that explicitly attempt to capture in their energy demand model specification, and subsequently (in two of the studies) in their empirical work, the concept that, consistent with the idea of demand being for energy services rather than energy itself, there is a role for energy efficiency to play. However, this key feature does not appear to have been implemented or further developed in any subsequent studies. Nevertheless, there is an associated strand of literature that has adopted ad hoc specifications of energy demand models, by including various forms of time trends, that are consistent with, and at least implicitly acknowledge, the idea that energy demand changes over time as energy efficiency changes. However, by their very nature, in such formulations the effects of energy efficiency are treated as being exogenous. For example, Beenstock and Willcocks $(1981,1983)$ introduce a linear time trend, although acknowledging its limitations. Later, Hunt et al. (2003a, 2003b), arguing that a linear trend is an inadequate way to capture technical progress and energy efficiency, suggesting that exogenous effects can be better captured via a stochastic trend - which they refer to as the underlying energy demand trend (UEDT). However, according to these authors, the UEDT includes more than just exogenous technical progress; it also includes exogenous change caused by such things as habit persistence, changes in values and lifestyles, changes in economic structure, changes in building and environmental regulations, etc., many of which may cause changes in energy efficiency.

While the approaches just described may indeed capture the effects of energy efficiency on energy demand, at least to some extent, a drawback is that they have no wellgrounded theoretical basis that indicates whether or in what way it is appropriate to include such terms in energy demand equations to capture efficiency effects. In part this stems from 
the continued focus on energy demand rather than the demand for energy services, since it is in the latter context that energy efficiency has a clearly defined role. It is not clear why practitioners continue to focus on energy demand rather than the demand for energy services, but this may be due, at least in part, to the fact that modeling demand for energy services was almost peripheral rather than the key focus of the papers by Walker and Wirl (1993) and Haas and Schipper (1998). Rather, in these studies, the main focus is on the irreversibility of technological progress, with the issue of interest becoming how to modify energy demand functions to deal with the irreversibility implication. However, focusing on the demands for the services that energy provides, rather than the demand for energy itself, opens up the possibility of examining more than just the irreversibility aspects of technical change. In particular, it allows a much clearer and more straightforward examination of issues such as rebound effects and asymmetric price responses, which comprise much of the motivation underlying the study by Goerlich and Wirl (2012).

As the preceding discussion highlights, one of the key aspects of focusing on energy services rather than energy itself concerns energy efficiency. In their empirical studies, both Walker and Wirl (1993) and Haas and Schipper (1998) construct measures of energy efficiency or its reciprocal, and include this in their models. However, this can be a painstaking and intrinsically unsatisfactory task, as there are multiple dimensions to energy efficiency as described above, and many will be difficult to observe although some attempt has been made to proxy this via a stochastic UEDT (Hunt et al., 2003a; 2003b). These difficulties may be an important reason for the lack of empirical attention explicitly given to the idea of modeling demands for energy services. These problems are further exacerbated by the argument that technical progress and therefore energy efficiency might be endogenous and consequently induced by past prices, so that any construction of an index of energy efficiency will typically ignore this feature. In the approach developed here our objective is 
to develop energy demand models that take account of demand being for energy services rather than energy itself, as well as the inherent endogeneity of energy efficiency, yet that can be estimated using the type of energy datasets that are readily available.

\section{Modelling the Demand for Energy Services}

In this section we develop a consumer utility maximization model in which utility is derived from consumption of energy services - rather than consumption of energy or of energy sources - as well as (potentially) from other non-energy goods. The conceptual approach in which utility is derived from energy services rather than energy itself appears to have a long history in energy economics, as many authors refer to derived demands for energy (see for example, Howarth, 1997; Hunt et al., 2003a, Haas et al., 2008; Fouquet and Pearson, 2012). However, apart from Walker and Wirl (1993), Hass and Schipper (1998), and Goerlich and Wirl (2012), there appear to have been no previous attempts to model this explicitly or to fully develop its implications.

We begin with a simple aggregate model in which there is just a composite energy good and a composite energy service, as well as a composite non-energy good, as this leads to the specification that is most similar to the single energy-consumption equation formulation that seems to be the backbone of empirical energy demand analysis. Even in this greatly simplified framework, consideration of consumer demand being for energy services rather than for energy itself yields a different model specification in which energy efficiency plays an explicit role. Next, we extend this analysis to a model in which there are various sources of energy (natural gas, electricity) each of which produces a single energy service (heating, lighting). Finally, we generalize this to a specification in which there are multiple energy sources each of which may produce multiple energy services, and multiple energy services (such as heating) which may be produced from several different energy sources. 
Issues involved in empirical implementation of the various models, which highlight the misspecification involved with typical energy demand function specifications, are examined in a subsequent section.

\subsection{Aggregate Energy Model}

In the consumer utility maximization model developed here, utility is derived from consumption of energy services, $S$, rather than consumption of energy itself, $E$, as well as from consumption of other goods, $X$. Thus, given the possibly unobserved price of energy services, $p_{s}^{*}$, and the observed price of other goods, $p_{X}$, as well as the income (or budget), $Y$, that is allocated among them, the consumer's problem is to determine $S$ and $X$ to:

$$
\operatorname{Max}\{U(S, X)\} \text { subject to } p_{S}^{*} S+p_{X} X=Y \text {. }
$$

Typically, neither the consumption of energy services nor the price of such services would be observed, although it may be in some cases, such as when there is a single energy source and a single energy service. Thus, it is necessary to consider the relationship between these measures and observed information about the price and consumption of energy. This involves the following two definitional relationships: ${ }^{3}$

(2) $\varepsilon=S / E$ and

(3) $p_{s}^{*}=p_{E} E / S=p_{E} / \varepsilon$

In (2), energy efficiency $(\varepsilon)$ is defined as the units of the energy service produced $(S)$ per unit of energy $(E){ }^{4}$ Thus, if more energy services can be produced using the same amount of energy, then efficiency has increased. In (3), the cost per unit of energy services, referred to as the per-unit price of such services, is defined as the cost of energy required to produce one

\footnotetext{
${ }^{3}$ See, for example, Sorrell and Dimitropoulos (2008), although this formulation is also evident in Walker and Wirl (1993).

${ }^{4}$ Note that this definition of efficiency abstracts from how efficient any particular equipment that is used to convert energy to energy services may be relative to other equipment that might be used to perform the same task.
} 
unit of those services, that is, the price per unit of the energy source divided by energy efficiency. Jointly, (2) and (3) imply:

(4) $p_{S}^{*} S=p_{E} E$,

that is, expenditure on energy services is equal to expenditure on the energy used to provide these services. Given this relationship, the budget constraint in (1) can be alternatively written as:

$$
p_{E} E+p_{X} X=Y \text {. }
$$

Since this is the same budget constraint that would be used if utility was defined over consumption of energy and other goods, it may appear that considering utility as a function of the services provided by energy rather than as a function of consumption of energy itself has no real effect. However, this is not the case. Specifically, from (1), the demand equations for $S$ and $X$ would be given by:

$$
S=S\left(p_{s}^{*}, p_{X}, Y\right) \text { and } X=X\left(p_{s}^{*}, p_{X}, Y\right) \text {, }
$$

so that substituting for $p_{s}^{*}$ in terms of $p_{E}$ using (3), and for $S$ in terms of $E$ using (2), we obtain:

(7a) $E=\frac{1}{\varepsilon} S\left(p_{s}^{*}, p_{X}, Y\right)=\frac{1}{\varepsilon} S\left(\frac{p_{E}}{\varepsilon}, p_{X}, Y\right)$, and

(7b) $\quad X=X\left(p_{s}^{*}, p_{X}, Y\right)=X\left(\frac{p_{E}}{\varepsilon}, p_{X}, Y\right)$.

For subsequent use, it is convenient to write the demand equations in (7a) and (7b) as expenditure equations:

$$
\begin{aligned}
& p_{E} E=\left(\frac{p_{E}}{\varepsilon}\right) S\left(\frac{p_{E}}{\varepsilon}, p_{X}, Y\right)=E^{*}\left(\frac{p_{E}}{\varepsilon}, p_{X}, Y\right), \text { and } \\
& p_{X} X=p_{X} X\left(\frac{p_{E}}{\varepsilon}, p_{X}, Y\right)=X^{*}\left(\frac{p_{E}}{\varepsilon}, p_{X}, Y\right)
\end{aligned}
$$

where $E^{*}($.$) and X^{*}($.$) are functional expressions for the expenditure on energy and on other$ goods, respectively. As can be seen from these functional expressions, the fundamental difference from the typical specification that is estimated is that the energy price term is expressed in efficiency units, that is, the price of energy is divided by energy efficiency. 
Obviously, if this efficiency term equals one, or some other constant - that is, if there is a fixed proportional relationship between consumption of energy and consumption of energy services - this will simplify to the usual specification where efficiency variables do not appear. Note, however, that estimation of equations such as $(8 \mathrm{a})$ and $(8 \mathrm{~b})$ require data over time or location (e.g., countries), with an additional subscript being added to all variables, so that to simplify to the usual specification it would be necessary for energy efficiency to be constant over time or location, which would seem unlikely.

\subsection{A Simple Model with Multiple Energy Sources and Services}

Next we extend this analysis to a model in which there are various sources of energy and various energy services, but to set the framework we begin with a simple specification in which each energy source produces only a single energy service, and where each energy service is provided by only a single energy source. For generality, other goods apart from energy services are included in the utility function, but the analysis could be restricted just to various energy services. ${ }^{5}$ Later, we generalize this framework to allow for the more realistic possibility that several energy sources produce the same type of energy service (e.g., heat), and each energy source may produce more than one energy service.

Initially, to simplify the analysis and notation, it is assumed that utility is derived from the consumption of two types of energy services - space heating $(h)$, and lighting $(l)$ - as well as consumption of other goods. For ease of notation, and to facilitate development of the more general model that we consider subsequently, it is also convenient to distinguish the "consumption services" provided by other goods, (oth), from the actual amount of other goods that are purchased, although this may be a one-to-one definitional relationship.

\footnotetext{
${ }^{5}$ This would be analogous to specifications where energy is assumed to be weakly separable from all other goods.
} 
Thus, given the (likely unobserved) prices of heating, lighting, and other services, $p_{h}^{*}$, $p_{l}^{*}$, and $p_{o t h}^{*}$, and an observed budget, $Y$, that is allocated among them, the consumer's problem is to determine $h, l$ and oth to:

$$
\operatorname{Max}\{U(h, l, o t h)\} \text { subject to } p_{h}^{*} h+p_{l}^{*} l+p_{\text {oth }}^{*} \text { oth }=Y \text {. }
$$

To provide a concrete example, suppose that space heating is provided using natural gas, $g$, while lighting is provided using electricity, $e$. Of course, natural gas may provide other services, such as water heating, and cooking services, and electricity also provides power for appliances and possibly heating services. Initially these complications are ignored, and it is assumed that each energy source only produces one type of energy service. It is similarly assumed that consumption services of other goods, oth, are only produced only by other goods, $o$.

Generalizing (2), the energy efficiency of each energy service is defined as the units of the service produced per unit of the corresponding energy source. ${ }^{6}$ Thus, if $\varepsilon_{h}$ is heating efficiency, $\varepsilon_{l}$ is lighting efficiency, and $\varepsilon_{\text {oth }}$ denotes the efficiency of providing consumption services of other goods (which would generally be equal to 1 ), ${ }^{7}$ then by definition,

$$
\varepsilon_{h}=\frac{h}{g} ; \quad \varepsilon_{l}=\frac{l}{e} ; \quad \varepsilon_{o t h}=\frac{o t h}{o},
$$

where $g, e$, and $o$ are the quantities of natural gas, electricity, and other goods, respectively. As a result, the cost per unit of heating services, which is equated to the (unobserved) price, $p_{h}^{*}$, is a function of heating efficiency, since if the heating efficiency is twice as great, this means that it would take half as much natural gas to produce the same amount of heat, and

\footnotetext{
${ }^{6}$ It is not necessary to be specific about the definition of a unit of each of these energy services, since the units of measurement of the efficiency variables will adjust to accommodate alternative choices of units of services.

${ }^{7}$ Note that if the analysis is just restricted to energy expenditures, with $Y$ defined as expenditure just on energy sources rather than total expenditure, then 'oth' could refer to services provided by oil products, for example, in which case $\varepsilon_{\text {oth }}$ would refer to the efficiency with which oil products produce energy services, and therefore need not equal one.
} 
the (variable) cost (that is, the cost of the natural gas used) would be half as much. Of course there would also be a capital cost associated with obtaining increased heating efficiency (e.g., a new furnace or boiler, or increased insulation), but it is assumed that this capital decision has been made in advance of the utilization decision. Hence, the budget, $Y$, available to be spent on the three goods would be net of the annualized capital costs. ${ }^{8}$

Thus, the relationship between the price of heating and the price of natural gas, $p_{g}$, between the price of lighting and the price of electricity, $p_{e}$, and between the price of the services provided by other goods and the price of other goods, $p_{o}$, is given by:

$$
p_{h}^{*}=\frac{p_{g}}{\varepsilon_{h}} ; \quad p_{l}^{*}=\frac{p_{e}}{\varepsilon_{l}} ; \quad p_{o t h}^{*}=\frac{p_{o}}{\varepsilon_{o t h}} .
$$

As a result of $(10)-(11)$, expenditure on heating, $p_{h}^{*} h$, equals expenditure on natural gas, $p_{g} g$, expenditure on lighting, $p_{l}^{*} l$, equals expenditure on electricity, $p_{e} e$, and expenditure on services provided by other goods, $p_{o t h}^{*} o t h$, equals expenditure on other goods, $p_{o} o$. Thus, using (10) and (11), the budget constraint in (9) can be alternatively written as:

$$
p_{g} g+p_{e} e+p_{o} o=Y
$$

Since this is the same budget constraint that would be used if utility was defined over consumption of natural gas, electricity, and other goods, it may again appear that considering utility as a function of the services provided by the various energy sources rather than as a function of the energy sources themselves has no real effect. However, this is not the case. Specifically, from (9), the demand equations for $h, l$, and oth would be given by:

$$
h=h\left(p_{h}^{*}, p_{l}^{*}, p_{o t h}^{*}, Y\right) ; l=l\left(p_{h}^{*}, p_{l}^{*}, p_{o t h}^{*}, Y\right) ; \quad \text { oth }=o t h\left(p_{h}^{*}, p_{l}^{*}, p_{o t h}^{*}, Y\right)
$$

Using (10) - (11) to substitute for $p_{h}, p_{l}$, and $p_{o t h}^{*}$ in terms of $p_{g}, p_{e}$, and $p_{o}$, and for $h, l$, and oth in terms of $g, e$, and $o$, we obtain:

(14a) $g=\frac{1}{\varepsilon_{h}} h\left(p_{h}^{*}, p_{l}^{*}, p_{\text {oth }}^{*}, Y\right)=\frac{1}{\varepsilon_{h}} h\left(\frac{p_{g}}{\varepsilon_{h}}, \frac{p_{e}}{\varepsilon_{l}}, \frac{p_{o}}{\varepsilon_{o t h}}, Y\right)$,

\footnotetext{
${ }^{8}$ The model could be generalized to include capital equipment purchasing decisions, but we do not consider this extension here.
} 
(14b) $e=\frac{1}{\varepsilon_{l}} l\left(p_{h}^{*}, p_{l}^{*}, p_{\text {oth }}^{*}, Y\right)=\frac{1}{\varepsilon_{l}} l\left(\frac{p_{g}}{\varepsilon_{h}}, \frac{p_{e}}{\varepsilon_{l}}, \frac{p_{o}}{\varepsilon_{o t h}}, Y\right)$, and

(14c) $o=\frac{1}{\varepsilon_{o}} \operatorname{oth}\left(p_{h}^{*}, p_{l}^{*}, p_{o t h}^{*}, Y\right)=\frac{1}{\varepsilon_{o t h}} \operatorname{oth}\left(\frac{p_{g}}{\varepsilon_{h}}, \frac{p_{e}}{\varepsilon_{l}}, \frac{p_{o}}{\varepsilon_{o t h}}, Y\right)$.

Thus, compared to commonly-used specifications, demands for all of the goods, including the various energy sources, depend on the prices of the energy sources, the price of other goods, the budget, and heating, lighting, and 'other' efficiency. Since, in a systems context, most commonly used functional forms (e.g., translog, Almost Ideal Demand System) involve estimation of a system of budget or expenditure share equations, it is convenient to write the demand equations in $(14 a),(14 b)$ and (14c) as expenditure share equations:

(15a) $s_{g}=\frac{1}{Y}\left(\frac{p_{g}}{\varepsilon_{h}}\right) h\left(\frac{p_{g}}{\varepsilon_{h}}, \frac{p_{e}}{\varepsilon_{l}}, \frac{p_{o}}{\varepsilon_{o t h}}, Y\right)=g\left(\frac{p_{g}}{\varepsilon_{h}}, \frac{p_{e}}{\varepsilon_{l}}, \frac{p_{o}}{\varepsilon_{o t h}}, Y\right)$.

(15b) $s_{e}=\frac{1}{Y}\left(\frac{p_{e}}{\varepsilon_{l}}\right) l\left(\frac{p_{g}}{\varepsilon_{h}}, \frac{p_{e}}{\varepsilon_{l}}, \frac{p_{o}}{\varepsilon_{o t h}}, Y\right)=e\left(\frac{p_{g}}{\varepsilon_{h}}, \frac{p_{e}}{\varepsilon_{l}}, \frac{p_{o}}{\varepsilon_{o t h}}, Y\right)$.

(15c) $\mathrm{s}_{\mathrm{o}}=\frac{1}{Y}\left(\frac{p_{o}}{\varepsilon_{o}}\right) \operatorname{oth}\left(\frac{p_{g}}{\varepsilon_{h}}, \frac{p_{e}}{\varepsilon_{l}}, \frac{p_{o}}{\varepsilon_{o t h}}, Y\right)=o\left(\frac{p_{g}}{\varepsilon_{h}}, \frac{p_{e}}{\varepsilon_{l}}, \frac{p_{o}}{\varepsilon_{o t h}}, Y\right)$,

where $s_{g}, s_{e}$, and $s_{o}$ are the expenditure shares for natural gas, electricity, and other goods, where, for example, $s_{g}=p_{g} g / Y$, etc.

As can be seen from these expressions, the fundamental difference from the typical system of energy demand equations specification that is estimated is that the price terms are all expressed in efficiency units, that is, the price of natural gas is divided by heating efficiency, the price of electricity is divided by lighting efficiency, etc. Obviously, if all these efficiency terms equal one, that is, there is a one-to-one relationship between consumption of the energy source and consumption of energy services - this will simplify to the usual specification where efficiency variables do not appear. Note that, as was the case for the equations derived for the aggregate model, the data that would be used in estimation would differ across time periods or individuals, so that there is an additional subscript added to all 
variables. Thus, to simplify to the usual specification it would be necessary that all the efficiency terms equalled one for all observations, which seems unlikely. ${ }^{9}$

Of course, the results derived here only hold when each energy source provides a single energy service, and each energy service is provided by only a single energy source. However, this one to one correspondence between energy services and energy sources is unlikely to hold in practice. For example, heating can be produced using natural gas (as in the simple model) or electricity, or possibly other energy sources, or possibly a combination of energy sources. Natural gas can produce space heating, cooking, and water heating (which may or may not be separate from space heating), and electricity can be used to produce lighting (as in the simple model), space and/or water heating, refrigeration, power for small appliances, etc. Therefore, we next consider a generalization of the simple model of the demand for energy services to allow for these possibilities.

\subsection{Generalized Model with Multiple Energy Sources and Services}

Here we consider the case where there are $n$ energy sources, indexed $i, j=1, \ldots, n$, each of which may produce more than one of $n^{*}$ energy services, indexed $m, q=1, \ldots, n^{*}$. For notational convenience, energy services are defined separately according to the energy source that is used to produce them. Thus, rather than considering heating as an energy service that can be produced using electricity or natural gas, or some other energy source or combination of energy sources, for modelling purposes heating produced by electricity is considered to be a different energy service to heating produced by natural gas. ${ }^{10}$

\footnotetext{
${ }^{9}$ Since there is no set definition of a unit of heating or of lighting, the scaling of the $\varepsilon_{j}$ is arbitrary, so it may be preferable to view the model as reducing to the usual specification if the $\varepsilon_{j}$ are the same for each service, for all observations, which seems equally unlikely.

${ }^{10}$ Although in both cases the end result is heating, it is often the case that efficiency improvements are for a particular energy service-energy source combination. Note that this way of modelling energy services does not preclude more than one energy source being used at the same time to produce these energy services, such as a boiler that produces heat using both electricity and natural gas.
} 
Using $x_{\mathrm{i}}$ to denote the quantity of the ith energy source or good, and $v_{\mathrm{m}}$ to denote the quantity of the $\mathrm{m}^{\text {th }}$ energy service, the efficiency of energy source $i$ used to produce energy service $m$ is given by $\varepsilon_{\mathrm{m}}$, where:

(16) $\varepsilon_{m}=\frac{v_{m}}{x_{i m}}$

where $x_{i m}$ is the quantity of energy source $i$ that is used to produce energy service $m$, so that

$$
x_{i}=\sum_{m \epsilon i} x_{i m}
$$

where $\sum_{m \epsilon i}($.$) refers to the sum over all energy services (m)$ that are provided by energy source $i$. As in the simple model, relationships analogous to (11) provide the links between the (unobserved) prices of the energy services $\left(p_{m}^{*}\right)$, each of which is provided uniquely by a single energy source, and the prices of the energy sources $\left(p_{i}\right)$. Specifically,

$$
p_{m}^{*}=\frac{p_{i}}{\varepsilon_{m}}, \quad i=1, \ldots, n ; m=1, \ldots, n^{*} ; m \epsilon i
$$

Thus, total expenditure on energy source $i$ is the sum of expenditure on all the services produced by that energy source, so that:

$$
p_{i} x_{i}=\sum_{m \epsilon i} p_{i} x_{i m}=\sum_{m \epsilon i} p_{m}^{*} v_{m}, \quad i=1, \ldots, n ; m=1, \ldots, n^{*} ; m \epsilon i \text {. }
$$

Hence, the budget constraint for the case where the household derives utility from consumption of energy services and other goods becomes $\sum_{\mathrm{m}=1}^{\mathrm{n}} p_{\mathrm{m}}^{*} v_{\mathrm{m}}=Y$ and the consumer's problem is to determine $\left\{v_{\mathrm{m}}, m=1, \ldots, n^{*}\right\}$ to:

$$
\operatorname{Max}\left\{U\left(v_{1}, v_{2}, \ldots, v_{n^{*}}\right)\right\} \text { subject to } \sum_{m=1}^{n^{*}} p_{m}^{*} v_{m}=Y,
$$

which yields derived demand equations for the services/goods given by:

$$
v_{m}=v_{m}\left(p_{1}^{*}, p_{2}^{*}, \ldots, p_{n^{*}}^{*}, Y\right)=v_{m}\left(\frac{p_{1}}{\varepsilon_{1}}, \frac{p_{1}}{\varepsilon_{2}}, \ldots, \frac{p_{n}}{\varepsilon_{n^{*}}}, Y\right)
$$

and hence expenditures on each energy service given by:

$$
p_{m}^{*} v_{m}=\left(\frac{p_{i}}{\varepsilon_{m}}\right) v_{m}\left(\frac{p_{1}}{\varepsilon_{1}}, \ldots, \frac{p_{n}}{\varepsilon_{n^{*}}}, Y\right),
$$

Although expenditure on energy service $m, p_{\mathrm{m}}^{*} v_{\mathrm{m}}$, is equal to expenditure on the amount of energy source $(i)$ used to produce that energy service, $p_{\mathrm{i}} x_{\mathrm{im}}$, this latter expenditure 
is generally unobserved unless energy source $i$ is used to produce only a single energy service. However, summing over all energy services produced by energy source $i$ yields $p_{i} x_{i}$, total expenditure on energy source $i$, which is observed. Specifically, dividing both sides of (19) by total expenditure, $Y$, and in conjunction with (22) yields expenditure share equations:

$$
\begin{aligned}
s_{i}=\frac{p_{i} x_{i}}{Y} & =\left(\frac{1}{Y}\right) \sum_{m \epsilon i} p_{m}^{*} v_{m}=\left(\frac{1}{Y}\right) \sum_{m \epsilon i}\left(\frac{p_{i}}{\varepsilon_{m}}\right) v_{m}\left(\frac{p_{1}}{\varepsilon_{1}}, \ldots, \frac{p_{n}}{\varepsilon_{n^{*}}}, Y\right) \\
& =s_{i}\left(\frac{p_{1}}{\varepsilon_{1}}, \ldots, \frac{p_{n}}{\varepsilon_{n^{*}}}, Y\right), i=1, \ldots, n .
\end{aligned}
$$

Thus, compared to the simple model considered previously, the only difference is that the price of each energy source appears (potentially) more than once in each expenditure share function, in each case divided by the respective efficiency term. Again, in contrast to standard energy demand equations, the key difference is that each energy price is divided by an efficiency term, and these terms are typically not included at all, let alone as the denominator of the price terms, in specifications that are typically estimated.

\section{Empirical Implementation of the Energy Services Models}

Next we consider empirical implementation of the models of energy services that were developed in the previous section. This analysis clearly identifies the misspecification problems that are implicit in the energy demand formulations that are typically estimated, and shows how they can be avoided. We begin here with the aggregate model, and then consider the generalized version of the model with multiple energy sources and services (which includes the simple version of this model as a special case). In a later section, a UK aggregate model is presented as an empirical example to illustrate the potential scope of such misspecification. 


\subsection{Aggregate Model}

For the aggregate model of energy services, we focus on the expenditure equations in (8a) and (8b). Since, via the budget constraint in (5), these two expenditures sum to income, $Y$, it is only necessary to consider one of the two equations. Here, since it is of most interest in the energy literature, we focus on the energy expenditure equation in (8a), that is, $p_{E} E=$ $E^{*}\left(\frac{p_{E}}{\varepsilon}, p_{X}, Y\right)$. The prevalent functional specification for an aggregate energy demand or expenditure equation is the double-logarithmic form which, ignoring the stochastic component(s) and other dynamic terms that are often included (which we discuss later), can be written as: ${ }^{11}$

$$
\ln \left(p_{E} E\right)=\beta_{1}+\beta_{2} \ln \left(\frac{p_{E}}{\varepsilon}\right)+\beta_{3} \ln p_{X}+\beta_{4} \ln Y
$$

which could be written equivalently as: ${ }^{12}$

$$
\begin{aligned}
& \ln \left(p_{E} E\right)=\beta_{1}+\beta_{2} \ln p_{E}+\beta_{3} \ln p_{X}+\beta_{4} \ln Y+\beta_{5} \ln \varepsilon, \text { or } \\
& \ln E=\beta_{1}+\beta_{2}^{*} \ln p_{E}+\beta_{3} \ln p_{X}+\beta_{4} \ln Y+\beta_{5} \ln \varepsilon
\end{aligned}
$$

where $\beta_{2}^{*}=\left(\beta_{2}-1\right)$. Imposing homogeneity of degree zero in prices and incomes (an implication of the budget constraint), these can be rewritten in real terms as:

$$
\begin{aligned}
& \ln \left(\frac{p_{E}}{p_{X}} E\right)=\beta_{1}+\beta_{2} \ln \left(\frac{p_{E}}{p_{X}}\right)+\beta_{4} \ln \left(\frac{Y}{p_{X}}\right)+\beta_{5} \ln \varepsilon, \text { or } \\
& \ln E=\beta_{1}+\beta_{2}^{*} \ln \left(\frac{p_{E}}{p_{X}}\right)+\beta_{4} \ln \left(\frac{Y}{p_{X}}\right)+\beta_{5} \ln \varepsilon,
\end{aligned}
$$

where $\left(\frac{p_{E}}{p_{X}} E\right)$ is real expenditure on energy, while $\mathrm{E}$ is the quantity of energy. Although there are implied parameter restrictions in these equations, namely $\beta_{5}=-\beta_{2}$ in (25) or (27),

\footnotetext{
${ }^{11}$ Note, however, that this functional form is not entirely consistent with the model in (8a) and (8b), since the double-logarithmic form cannot satisfy the adding-up conditions implicit in the budget constraint, that is, that the sum of expenditure on the two goods equals total expenditure. Further, to avoid the restriction of constant price elasticities over time, a more flexible functional form would be required. An alternative possibility is considered subsequently.

${ }^{12}$ However, the different left-hand side variables in (25) and (26) have potentially different implications for the stochastic specification, and when lagged dependent variables are included as part of the specification.
} 
and $\beta_{5}=-\left(1+\beta_{2}^{*}\right)$ in (26) or (28), these will generally not need to be imposed due to the way in which the energy efficiency variable is specified, which we consider later.

Thus, in terms of empirical implementation, the only change that occurs when account is taken of demand being for energy services rather than for energy itself, is the addition to the estimating equations of a term involving the (natural logarithm of the) energy efficiency variable. Hence, focusing on demand for energy (as is typically done) rather than demand for energy services is tantamount to omitting this term from the estimating equations. Unless this term is constant across observations, estimation by standard methods will result in omitted variable bias, and this has implications for the price elasticities and other measures that would be determined from such an equation.

In the specification in (28), the own-price energy elasticity is given by $\eta_{p_{E}}(E)=$ $\frac{\partial \ln E}{\partial \ln p_{E}}=\beta_{2}^{*}$, while in specification $(27), \eta_{p_{E}}(E)=\left(\beta_{2}-1\right)$. For both (27) and (28), the own-price elasticity is restricted to be constant throughout the sample period, which is arguably a drawback, given the evidence from Walker and Wirl (1993), Haas and Schipper (1998), and Ryan and Plourde (2002), among others, that such a restriction is inappropriate. We therefore also consider an alternative functional specification.

A popular more flexible functional form that could be used is the Linearized version of the Almost Ideal Demand System (LAIDS), introduced by Deaton and Muellbauer (1980). In this case, the expenditure equations in ( $8 \mathrm{a})$ and $(8 \mathrm{~b})$ would be replaced by expenditure share equations. As shown in Ryan (2014), use of LAIDS with the aggregate energy services model, again with homogeneity and the adding-up conditions applied, leads to the following functional form for the energy equation:

$$
s_{E}=\alpha_{1}+\alpha_{2} \ln \left(\frac{p_{E}}{p_{X}}\right)+\alpha_{4} \ln \left(\frac{Y}{P}\right)+\alpha_{5} \ln \varepsilon,
$$


where $s_{E}=\left(\frac{p_{E} E}{Y}\right)$ is the share of income that comprises expenditure on energy, $\alpha_{5}=-\alpha_{2}$, and $\ln P$ is the predetermined (prior to estimation) Stone Price Index, defined here as:

$$
\ln P=s_{E} \ln p_{E}+\left(1-s_{E}\right) \ln p_{X} .
$$

In this case, the energy own price elasticity is given by: ${ }^{13}$

$$
\eta_{p_{E}}(E)=\frac{\partial E}{\partial p_{E}} \frac{p_{E}}{E}=\frac{\alpha_{2}}{s_{E}}-\alpha_{4}-1
$$

which is not constant since $s_{E}$ varies across observations.

\subsection{Generalized Model with Multiple Energy Sources and Services}

Next we consider empirical implementation of the general model with multiple energy sources and energy services using typically available data that pertain just to consumption and prices of energy sources. Since it is used so frequently in empirical analysis, the specification considered here is again the Linearized version of the Almost Ideal Demand System (LAIDS), although similar analysis could be undertaken using alternative functional formulations. For LAIDS, the expenditure share equations are derived from a cost function rather than a utility function, but the outcome in terms of the preceding analysis is unchanged. Following Deaton and Muellbauer (1980), the equations for the expenditure shares for each energy service, $\mathrm{s}_{\mathrm{m}}^{*}=\frac{p_{m}^{*} v_{m}}{Y}=\frac{p_{i} x_{i m}}{Y}$, have the form:

$$
s_{m}^{*}=\alpha_{m}^{*}+\sum_{q} \gamma_{m q}^{*} \ln \left(p_{q}^{*}\right)+\beta_{m}^{*}\left(\ln Y-\ln P^{*}\right), \quad m, q=1, \ldots, n^{*},
$$

In the linearized form of the AIDS model, the price index, $\ln P^{*}$ in (32) is replaced by a predetermined price index, such as the Stone Price Index:

$$
\ln P^{*}=\sum_{i=1}^{n} \sum_{m \epsilon i} s_{m}^{*} \ln p_{i}=\sum_{i=1}^{n} \ln p_{i}\left(\sum_{m \epsilon i} s_{m}^{*}\right)=\sum_{i=1}^{n} s_{i} \ln p_{i}=\ln P
$$

\footnotetext{
${ }^{13}$ See Buse (1994) for an evaluation of the various possible elasticity expressions that can be used with the LAIDS model. This expression is the most widely used and, according to Buse's results, is marginally the best.
} 
where $s_{\mathrm{i}}=\sum_{m \in i} s_{m}^{*}$, so that $\ln P^{*}$ simplifies to the usual Stone Price Index defined over energy sources, $\ln P=\sum_{j=1}^{n} s_{j} \ln p_{j} \quad$ Since, from $(18), \ln \mathrm{p}_{\mathrm{q}}^{*}=\ln \left(\mathrm{p}_{\mathrm{j}} / \varepsilon_{\mathrm{q}}\right)=\ln \mathrm{p}_{\mathrm{j}}-$ $\ln \varepsilon_{\mathrm{q}}, j=1, \ldots, \mathrm{n} ; q=1, \ldots, \mathrm{n}^{*} ; \mathrm{q} \in \mathrm{j},(32)$ can be re-written as:

$$
\begin{aligned}
s_{m}^{*}= & \alpha_{m}^{*}+\sum_{j=1}^{n} \sum_{q \epsilon j} \gamma_{m q}^{*} \ln \left(\frac{p_{j}}{\varepsilon_{q}}\right)+\beta_{m}^{*}(\ln Y-\ln P) \\
= & \alpha_{m}^{*}+\sum_{j=1}^{n} \sum_{q \epsilon j} \gamma_{m q}^{*} \ln \left(p_{j}\right)-\sum_{q} \gamma_{m q}^{*} \ln \left(\varepsilon_{q}\right)+\beta_{m}^{*}(\ln Y-\ln P), \\
& m, q=1, \ldots, n^{*}, \text { where } \sum_{j=1}^{n} \sum_{q \epsilon j} \gamma_{m q}^{*} \ln \left(\varepsilon_{q}\right)=\sum_{q} \gamma_{m q}^{*} \ln \left(\varepsilon_{q}\right) .
\end{aligned}
$$

In the general case, different energy services are provided by the same energy source, and thus face the same price for that energy source (but possibly have different efficiencies), while unobserved budget shares for different energy services provided by a specific energy source sum to the observed budget share for that energy source. Thus, (34) can be aggregated by summing across all the different energy services provided by each of the $\mathrm{n}$ energy sources $\left(\sum_{\mathrm{m} \in \mathrm{i}} S_{\mathrm{m}}^{*}\right)$ to yield the following system of budget share equations, one for each energy source (or good):

$$
s_{i}=\alpha_{i}+\sum_{j} \gamma_{i j} \ln p_{j}+\beta_{i}(\ln Y-\ln P)+\left[T E R M_{i}\right], \quad i, j=1, \ldots, n,
$$

where

$$
\alpha_{i}=\sum_{m \epsilon i} \alpha_{m}^{*} ; \beta_{i}=\sum_{m \epsilon i} \beta_{m}^{*} ; \gamma_{i j}=\sum_{m \epsilon i} \sum_{q \epsilon j} \gamma_{m q}^{*} ; s_{i}=\sum_{m \epsilon i} s_{m}^{*}, i, j=1, \ldots, n,
$$

and $\sum_{m \epsilon i}($.$) refers to the sum over all energy services (m)$ that are provided by energy source (i), where $i, j=1, \ldots, n$ index the $\mathrm{n}$ energy sources and/or goods, and

$$
\operatorname{TERM}_{i}=-\sum_{m \epsilon i}\left(\sum_{q} \gamma_{m q}^{*} \ln \varepsilon_{q}\right)
$$

Note that the usual adding-up conditions (since the sum of the budget shares is 1), along with homogeneity and symmetry, which apply to the energy services share equations in (32) or (34), have implications for the parameters in the energy sources share equation (35). In particular, adding-up requires:

$$
\sum_{m} \alpha_{m}^{*}=1 ; \quad \sum_{m} \gamma_{m q}^{*}=0 \text { for all } q ; \quad \sum_{m} \beta_{m}^{*}=0 ; \quad m, q=1, \ldots, n^{*}
$$


while homogeneity and symmetry require:

$$
\sum_{q} \gamma_{m q}^{*}=0 \text { for all } m ; \text { and } \gamma_{m q}^{*}=\gamma_{q m}^{*}, \quad m, q=1, \ldots, n^{*}
$$

As can be seen from the definitions in (36), $\gamma_{\mathrm{mq}}^{*}=\gamma_{\mathrm{qm}}^{*}, m, q=1, \ldots, \mathrm{n}^{*}$, implies that $\gamma_{\mathrm{ij}}=\gamma_{\mathrm{ji}}, \mathrm{i}, \mathrm{j}=1, \ldots, \mathrm{n}$, while $\sum_{\mathrm{m}} \alpha_{\mathrm{m}}^{*}=1 \rightarrow \sum_{\mathrm{i}} \alpha_{\mathrm{i}}=1 ; \sum_{\mathrm{m}} \beta_{\mathrm{m}}^{*}=0 \rightarrow \sum_{\mathrm{i}} \beta_{\mathrm{i}}=0 ;$ and $\sum_{\mathrm{m}} \gamma_{\mathrm{mq}}^{*}=\sum_{\mathrm{q}} \gamma_{\mathrm{mq}}^{*}=0 \rightarrow \sum_{\mathrm{j}} \gamma_{\mathrm{ij}}=\sum_{\mathrm{i}} \gamma_{\mathrm{ij}}=0$. Thus, the same conditions that apply to (32) or (34) apply to the re-parameterized specification in (35). Of course, for (35) to satisfy adding up it is also necessary that $\sum_{\mathrm{i}}\left[\mathrm{TERM}_{\mathrm{i}}\right]=0$, which can be shown to hold given the restrictions in (38). ${ }^{14}$

To summarize, in terms of empirical implementation, the only change that occurs with the LAIDS model when consumers determine demands for energy services rather than for energy sources, is the addition to each of the estimating equations for the expenditure shares of TERM ${ }_{i}$ defined in (37). Apart from this term, even though energy services might be provided by multiple energy sources, and any particular energy source may provide several different types of energy services, the system of equations that would be estimated when the model is specified in terms of energy services would be the same as the system that would typically be estimated when utility is defined simply over energy sources (and possibly goods), and the usual parameter restrictions would be appropriate. In particular, expenditure shares would still be defined in terms of energy sources, and the price terms in the estimating equations would still refer to the prices of these energy sources. Thus, focusing on demands for energy sources (as is typically done) rather than demands for energy services is

\footnotetext{
${ }^{14}$ Note that if the efficiency terms were also to be introduced in the Stone Price Index in (33), by defining $\ln P^{*}=\sum_{m=1}^{n^{*}} s_{m}^{*} \ln p_{m}^{*}=\ln P-\sum_{m=1}^{n^{*}} s_{m}^{*} \ln \varepsilon_{m}^{*}, T E R M_{i}$ in (37) would become $-\left[\sum_{m \epsilon i}\left(\sum_{q} \gamma_{m q}^{*} \ln \varepsilon_{q}\right)-\beta_{i} \sum_{m} s_{m}^{*} \ln \varepsilon_{m}^{*}\right]$. Typically, since the Stone Price Index is used as an approximation to linearize the share equations, and since introducing unobserved efficiency terms into (33) would mean that $\ln P^{*}$ could not be determined prior to estimation and would therefore result in all current period shares appearing as explanatory variables in each share equation, (33) would not be defined in this way.
} 
tantamount to omitting $\mathrm{TERM}_{\mathrm{i}}$ from the usual estimating equations. In other words, the key difference that arises from the consideration of energy services is this extra expression, $\mathrm{TERM}_{\mathrm{i}}$, which involves the $\ln \varepsilon_{\mathrm{q}}$, terms that (in natural logarithms) reflect the energy efficiency of the various energy sources when used to produce particular energy services. ${ }^{15}$ Under certain, though unlikely conditions, this omission will be unimportant. These include when efficiency is equal to 1 for all energy services and for all observations ( $\ln \varepsilon_{q \mathrm{t}}=0$ ), or when efficiency is the same for all energy services, even if the level of this efficiency differs over time, $\left(\ln \varepsilon_{q \mathrm{t}}=\theta_{t}\right)$, in which case $\mathrm{TERM}_{\mathrm{i}}$ will disappear with the homogeneity conditions (39). Even if efficiency differs for different energy services but is constant over time $\left(\ln \varepsilon_{q \mathrm{t}}=\theta_{q}\right), \mathrm{TERM}_{\mathrm{i}}$ will be absorbed into the intercept. However, in any other circumstances, such as when there are differences in efficiency and variation over time, as would be expected, then estimation of (35) (incorporating (33)) without including the efficiency terms $\left(\right.$ TERM $\left._{\mathrm{i}}\right)$ will result in omitted variables bias. As is well known, this has important implications for price elasticities and other measures that would be determined from the estimated parameters of such a system.

With the LAIDS version of (35), the price elasticities for the various energy sources for the LAIDS model can be calculated from the estimated parameters using the relationship (Buse, 1994):

$$
\eta_{i j}=\eta_{p_{j}}\left(x_{i}\right)={ }^{\gamma_{i j}} / s_{i}-\beta_{i}\left(s_{j} / s_{i}\right)-\delta_{i j}, \quad i, j=1, \ldots, n
$$

where $\delta_{i j}=1$ if $i=j$, and $=0$ otherwise. Of course these price elasticities are only appropriate if energy efficiency is explicitly incorporated in the model (via TERM ${ }_{\mathrm{i}}$ ).

\footnotetext{
${ }^{15}$ The analysis here has utilized the Linear AIDS model. Deaton and Muellbauer (1980) also consider a nonlinear version of the AIDS where $\ln P^{*}$ in (32) is essentially a translog function of prices involving mostly the same unknown coefficients as appear in the rest of the model. In this case, $\mathrm{TERM}_{\mathrm{i}}$ would also include the cross products of the efficiency measures with the prices of the energy sources, and the cross products of the efficiency measures.
} 


\section{Approaches to Modelling Unobserved Energy Efficiency}

As can be seen from the estimating equation for the energy demand function for the aggregate model, in (27), (28), or (29), as well as for the energy source expenditure share equations in (35), the key difference from the specifications that are typically estimated is the addition to these equations of a term involving the energy efficiency variables. Of course if data were available directly on these efficiency variables, or could be used to construct an index of efficiency, such variables or indexes could be used directly in the energy demand equations. This is the approach used by Haas and Schipper (1998) and in a different way by Walker and Wirl (1993). However, in general, such data are not readily available, except for some specific applications, and any index that is constructed is unlikely to include all the characteristics that define energy efficiency. Further, constructing such indexes and then including them in the model ignores the endogeneity of energy efficiency, including its possible dependence on the past movements in energy prices and/or other variables.

Another issue concerns exactly what efficiency should capture. In (2), efficiency is defined as the amount of energy services produced per unit of energy and although Walker and Wirl (1993) use this same definition, in constructing their efficiency measure for use in a transportation demand model, they take pains to exclude the reversible part, noting that:

"The efficiency series ... must measure the technological efficiencies and not the observed efficiencies which are affected by numerous car attributes that are reversible. ... a low gasoline price (e.g. after 1985), may lead to a reduction in observable efficiencies due to the purchase of larger cars despite the improved efficiencies of new models. Therefore, observed and published figures on actual efficiencies do not capture the technological efficiency and are not very useful for our purpose." (p. 195).

But arguably this entirely misses the point. If consumers are purchasing less efficient equipment (larger cars, for example) even though more efficient equipment is available, then energy demand is affected. Energy demand does not just respond to the highest level of efficiency that is available. As energy prices fall, the efficiency knowledge that has been 
accumulated does not decrease, but the use of it may. In this sense, simply taking account of the irreversibility of efficiency knowledge in energy demand functions is not sufficient. More importantly, it is necessary to take account of how consumers respond in terms of their energy purchases. What is needed is not just a unidirectional, non-decreasing index or filter that reflects the state of technical efficiency knowledge, but rather a function that indicates how the factors that have induced that state of knowledge also affect the extent to which consumers make use of it in their purchases, that is, a function in which the determinants of observed efficiency are allowed to play their roles.

In view of this feature, the approach we develop involves specifying the energy efficiency term $(\varepsilon)$ or terms $\left(\varepsilon_{q}, q=1, \ldots, n^{*}\right)$ to be functions of observed variables and unknown parameters. Thus, data on energy efficiency itself is not required; all that is needed is information on the variables that affect energy efficiency. Including an observation subscript, $t$, on the variables in the model, the efficiency terms are therefore specified as:

$$
\ln \varepsilon_{q t}=f_{q}\left(Z_{1 t}, Z_{2 t}, \cdots, Z_{s t}\right), \quad q=1, \ldots, n^{*}, t=1, \ldots, T
$$

where the subscript ' $q$ ' indicates that the function may differ for different energy services. Note that while the elasticities in (31) or (40), or those calculated using (27) or (28), do not depend explicitly on the particular variables included in these efficiency functions or their corresponding estimated coefficients, these aspects of the specifications will of course potentially affect the values of all the other estimated parameters in the model, as well as the estimated shares that appear in (31) and (40), and therefore the values of the elasticities.

There are a number of possible types of explanatory variables that might determine (the natural logarithm of) energy efficiency for each energy service given in (41). These could include: 


\section{Exogenous trends}

The simplest version allows energy efficiency to follow a simple deterministic trend $(t)$, and such an approach would implicitly be consistent with many previous studies. However, given some of the arguments against such a simplistic approach (summarized in Hunt et al., 2003a; 2003b), nonlinear trends are likely to be more appropriate. Thus, an alternative approach would be to include $t$ and $t^{2}$ together, or a more general stochastic trend (or UEDT, as discussed in Hunt et al., 2003a; 2003b).

\section{Past energy prices}

An increase in the price of energy sources is likely to provide the motivation for technical change that improves the efficiency of the delivery of household energy services (such as heating using natural gas). This suggests that energy efficiency will be a function of past prices of various energy sources, not necessarily just the one that is used to provide the energy services being considered, since substitution is possible. Alternatives for the lagged energy source price terms include relative prices, real prices, or growth rates.

\section{Past Energy Price Components}

A number of authors (such as Gately and Huntington, 2002) have estimated energy demand models that allow for asymmetric responses to price changes based on the idea that when energy prices rise, households make irreversible energy efficiency investments that reduce their responsiveness to energy demand, even if energy prices were subsequently to decrease. Therefore, the types of terms used to allow for asymmetric effects, as considered by Gately and Huntington (2002) (among others), could be also be possible explanatory variables that determine (the natural logarithm of) energy efficiency. 


\section{Illustrative Empirical Example}

The main contribution of this paper is the introduction of an analytical model that takes account of how energy is demanded not for its own sake but for the services it provides. This was done at both a macro level (a single aggregate energy service) as well as a micro level (demands for various energy services), and various ways of empirically implementing both types of models were presented. As was shown, demands for energy services can readily be converted and/or aggregated into demands for particular energy sources, or for aggregate energy. However, the resultant energy demand functions differ from those that are typically estimated in that they involve additional terms that reflect the efficiency with which energy is converted into the energy services that are provided. We have outlined various ways that this energy efficiency can be modelled in the case where data on efficiency are not readily available. Such modelling is a rich area for future research, as is estimation of a variety of models based on the energy services specification, and we do not attempt to undertake such an ambitious exercise here. Rather, in this section we provide an illustrative empirical example, using UK data, of just one particular formulation (the aggregate energy services model) using one possible type of specification for energy efficiency (the exogenous trends approach).

\subsection{Specifications}

The basis for our illustrative examination of how the explicit modelling of energy services impacts on estimated energy demand relationships is the simple aggregate model, equation (28), which is estimated for the UK whole economy. We begin with a 'base' benchmark model (Base) that excludes any extra terms that result from explicitly incorporating energy services in the consumer utility maximizing framework (i.e. the $\beta_{5} \ln \varepsilon$ term in (28) is excluded). This is then compared with two 'augmented' models that capture the effect of including efficiency using two forms of the exogenous trends approach discussed in the 
previous section: ${ }^{16}$ Model A1 adds $t$ and $t^{2}$, (where $t$ is a time trend $t=1,2,3, \ldots$ ); and Model A2 adds $\mu_{t}$, a stochastic trend/UEDT, where:

$$
\begin{array}{rlrl}
\text { (43) } \mu_{t} & =\mu_{t-1}+\gamma_{t-1}+\varphi_{t} ; & & \varphi_{t} \sim \text { iid } N\left(0, \sigma_{v}^{2}\right), \text { and } \\
\text { (44) } \quad \psi_{t}=\psi_{t-1}+\omega_{t} ; & \omega_{t} \sim \text { iid } N\left(0, \sigma_{\omega}^{2}\right) .
\end{array}
$$

Consistent with typical energy demand equations, all models (Base, A1 and A2) include a weather-related (temperature) variable $\left(T J_{t}\right)$. In addition, to allow for the possibility of dynamics and to help ensure that the error terms are well behaved, the models are specified as ARDL(2) models in the energy $\left(E_{t}\right)$, real energy price $\left(P_{t}\right)$ and real income $\left(Y_{t}\right)$ variables: ${ }^{17}$

$$
A(L) \ln E_{t}=B(L) \ln P_{t}+C(L) \ln Y_{t}+\theta T J_{t}+e_{i t} \quad \mathrm{t}=1967, \ldots, 2011,
$$

where $A(L), B(L)$, and $C(L)$ are polynomial lag operators $\left(1-a_{1} L-a_{2} L^{2}\right),\left(1+b_{1} L+\right.$ $\left.b_{2} L^{2}\right)$, and $\left(1+c_{1} L+c_{2} L^{2}\right)$, respectively, $B(L) / A(L)$ and $C(L) / A(L)$ represent the long run price and income elasticities respectively, and $e_{i t}$ is a random error term. Given that a stochastic trend is included in the second augmented model (A2), it is estimated using STAMP 8.10 (Koopman et al., 2007). The base model (Base) and the first augmented model (A1) can be estimated using a more standard software package such as PcGive 12.10 (Doornik and Hendry, 2007), which yields a richer set of diagnostics and has better testing procedures. To facilitate comparisons of the diagnostics for the different model specifications, the Base and A1 models are estimated using both PcGive and STAMP.

\footnotetext{
${ }^{16}$ At this stage these specifications are just meant to be illustrative; the energy services model developed earlier is sufficiently rich to allow many other possibilities as discussed in the previous section, and some others, particularly those where energy efficiency is dependent on past prices, may be preferable.

${ }^{17}$ Exact definitions of the variables used in the estimation are given in the following sub-section.
} 


\subsection{Data.}

The primary source of UK data is the International Energy Agency (IEA) database. $E$ is whole-economy total energy consumption in thousand tonnes of oil equivalent (ktoe) and $Y$ is GDP in billion 2005 US\$ using PPPs (both from IEA, 2013a). The index of real energy prices $(2005=100)$ is also taken from the IEA database (IEA, 2013b) but is only for the period 1978-2011. This is therefore spliced with an aggregate real price index for each country derived from data in Baade (1981); calculated by weighting gas in households and industry, coal in households and industry, electricity in households and industry, gasoline, diesel fuel and kerosene by their fuel consumption shares. ${ }^{18}$ This produces a real aggregate energy price index for each country in 1972 prices $(1972=100)$ over the period 1960 to 1980 . The two series $(1960-1980 ; 1972=100)$ and $(1978-2006 ; 2000=100)$ are subsequently spliced using the ratio from the overlap year 1978 to obtain the real energy price index, denoted by $\mathrm{P}$, over the period 1960 to 2011 at 2005 prices $(2005=100)$. The weather variable $T J$ is the average January temperature in degrees Celsius for Great Britain, taken from various issues of the UK Digest of Energy Statistics (DUKES).

\subsection{Estimation Results}

Table 1 presents the estimation results for the base Model (Base) and the two augmented models (A1 and A2). ${ }^{19}$ This shows that all models pass an array of residual diagnostic tests, for A2 the auxiliary residuals for the hyper-parameters are normally distributed, and the temperature variable is significantly different from zero in all models.

\footnotetext{
${ }^{18}$ This source was used in a similar way by Prosser (1985), Adeyemi et al. (2010) and Adofo et al. (2013).

${ }^{19}$ An advantage of the specification in A2, where the structural time series model (STSM) is used with the stochastic trend, is that it is not necessary to consider issues of unit roots and cointegration (Harvey, 1997). This is not formally the case with A1, but given that the results for both A1 and A2 are reasonably similar, and since this example is just meant to be illustrative, we have not explicitly considered this issue.
} 
Table 1: Estimation Results (Dependent Variable $\ln E_{t}$ )

\begin{tabular}{|c|c|c|c|}
\hline Model & Base & A1 & A2 \\
\hline $\begin{array}{l}\text { Estimated Long Run Elasticities } \\
\text { Price } \\
\text { Income }\end{array}$ & $\begin{array}{r}-0.79[0.05] \\
0.18[0.05]\end{array}$ & $\begin{array}{r}-0.30[0.00] \\
0.69[0.00]\end{array}$ & $\begin{array}{c}-0.11^{\#} \\
0.56^{\#}\end{array}$ \\
\hline $\begin{array}{l}\text { Estimated Coefficients } \\
\text { January Temperature } \\
\text { Trend } \\
\text { Trend Squared }\end{array}$ & $-0.0050[0.03]$ & $\begin{array}{l}-0.0057[0.01] \\
-0.0009[0.75] \\
-0.0001[0.00]\end{array}$ & $-0.0058[0.00]$ \\
\hline $\begin{array}{l}\text { Estimated Hyper-parameters } \\
\text { Irregular } \\
\text { Level } \\
\text { Slope } \\
\end{array}$ & & & $\begin{array}{r}0.000230 \\
------ \\
0.000024 \\
\end{array}$ \\
\hline $\begin{array}{l}\text { PcGive Diagnostics } \\
\text { S.E. } \\
R^{2} \\
\text { AIC } \\
\text { SC } \\
\text { AR(1-2) } \\
\text { ARCH(1-1) } \\
\text { Normality } \\
\text { Heteroscedasticity } \\
\text { RESET } \\
\text { Test Against Base }\end{array}$ & $\begin{array}{r}0.021 \\
0.935 \\
-7.5281 \\
-7.1457 \\
1.96[0.16] \\
0.04[0.85] \\
4.05[0.13] \\
1.26[0.30] \\
2.17[0.15]\end{array}$ & $\begin{array}{r}0.019 \\
0.948 \\
-7.6782 \\
-7.2193 \\
0.61[0.55] \\
0.44[0.51] \\
0.85[0.65] \\
1.08[0.44] \\
0.94[0.34] \\
4.91[0.01]\end{array}$ & \\
\hline $\begin{array}{l}\text { STAMP Diagnostics } \\
\mathrm{r}_{(1)} \\
\mathrm{Q} \\
\text { Normality } \\
\mathrm{H}_{(\mathrm{h})} \\
\text { Auxiliary residuals: } \\
\quad \text { Normality - Irregular } \\
\quad \text { Normality - Level } \\
\quad \text { Normality - Slope }\end{array}$ & $\begin{array}{r}-0.10 \\
4.62[0.46] \\
2.15[0.34] \\
1.20[0.37]\end{array}$ & $\begin{array}{r}-0.13 \\
5.09[0.40] \\
1.00[0.61] \\
0.99[0.51]\end{array}$ & $\begin{array}{r}-0.14 \\
5.87[0.32] \\
2.57[0.28] \\
1.28[0.33] \\
\\
1.39[0.50] \\
------- \\
3.30[0.19]\end{array}$ \\
\hline
\end{tabular}

Notes.

(i) The estimation period for all models is 1962-2011.

(ii) $[0.00]$ represents probability levels $\left({ }^{\#}\right.$ denotes that the probabilities of the long-run elasticities cannot be extracted from STAMP).

(iii) For the PcGive Diagnostics:

- $\quad$ S.E. and $R^{2}$ refer to the estimated Standard Error and Coefficient of Determination respectively;

- $\quad \mathrm{AIC}$, and SC refer to the Akaike Information Criterion and the Schwarz Criterion respectively;

- $\quad$ AR(1-2) refers to the F-test test for $2^{\text {nd }}$ order residual autocorrelation;

- $\mathrm{ARCH}(1-1)$ refers to the F-test for $1^{\text {st }}$ order AutoRegressive Conditional Heteroscedasticity;

- $\quad$ Normality refers to the Doornik and Hansen $\chi^{2}$-test for normality;

- Heteroscedasticity refers to the F-test for heteroscedasticity test using squares;

- $\quad$ RESET refers to the F-test Regression Specification Test; and

- Test Against Base refers to the exclusion F-Test for Trend and Trend Squared.

(iv) For the STAMP Diagnostics:

- $\mathrm{r}_{(1)}$ is the residual autocorrelation at lag 1 ;

- Q refers to the Box-Ljung $\chi^{2}$-test for $6^{\text {th }}$ order residual autocorrelation;

- Normality refers to the Bowman-Shenton $\chi^{2}$-test for normality;

- $\mathrm{H}_{(\mathrm{h})}$ refers to the F-test for heteroscedasticity; 
When comparing A1 with Base it can be seen that $R^{2}$ and the information criteria (AIC and SC) all suggest that A1 is preferred. Moreover, the test of A1 against Base suggests that the two extra variables $t$ and $t^{2}$ included in the augmented model to capture the impact of energy efficiency are jointly significantly different from zero; thus supporting the idea that these extra terms to represent the efficiency are required in the model. While A2 cannot be formally tested against Base, the comparable coefficient estimates are similar in A2 and A1. Figure 2 shows the similarity between the shapes of the estimated exogenous trend from A1 and the estimated stochastic trend from A2, with both suggesting that energy efficiency has, ceteris paribus, reduced aggregate energy demand over the estimation period. $^{20}$

Figure 1: Estimated Exogenous Trends to Capture Effects of Energy Efficiency

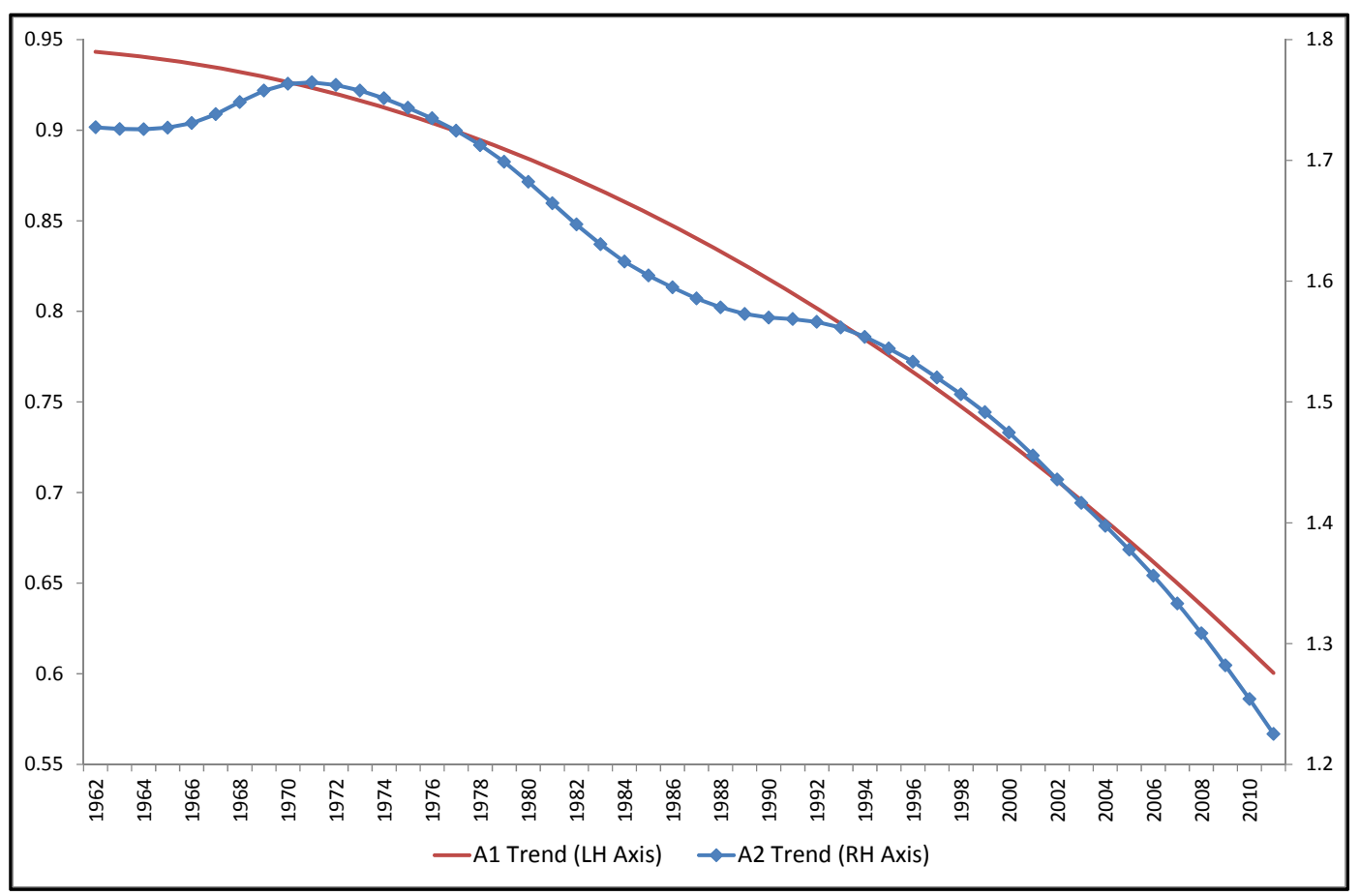

\footnotetext{
${ }^{20}$ The estimated long run elasticities from A2 and the shape of the trend are similar to those obtained by Dimitropoulos et al. (2005) who use a different data source and data period and test down from an ARDL(4) model to a preferred specification.
} 
Table 2 summarizes the estimated long run price and income elasticities from the different models. This shows that the estimated long run income elasticity is somewhat higher in the augmented models than in the base model, whereas the estimated long run price elasticity is somewhat lower (in absolute terms). This illustrates that the explicit modelling of energy services impacts the estimated own-price and income elasticities, indicating that results obtained from estimation of standard 'energy demand' relationships that do not consider energy service demand are likely to result in biased elasticity estimates.

Table 2 Estimated Price and Income Elasticities

\begin{tabular}{|c|c|c|}
\hline \multirow{2}{*}{ Models } & \multicolumn{2}{|c|}{ Long Run Elasticities } \\
& Price & Income \\
\hline Base & -0.79 & 0.18 \\
A1 & -0.30 & 0.69 \\
A2 & -0.11 & 0.56 \\
\hline
\end{tabular}

\section{Summary and Conclusions}

Although energy is typically demanded for the services it provides rather than for its own sake, this feature is rarely considered explicitly in empirical energy demand analysis. We demonstrate here how this oversight results in typical energy demand equations being misspecified, likely resulting in biased estimates of price and income elasticities and other measures that are obtained using the parameter estimates. We do this by developing a model of consumer behaviour in which utility derives from consumption of energy services rather than from the energy sources that are used to produce them. We consider both a formulation that yields an aggregate demand equation for energy services as well as one that yields a system of demand equations for particular types of energy services. In both cases, we show how, for empirical implementation, these can be readily converted, without added complexity, into the standard type of energy demand equation(s) that is (are) typically estimated. However, compared to these typical energy demand equations, those that we 
obtain here include additional terms that reflect the efficiency with which energy is converted into various energy services. This highlights the misspecification that is implicit when typical energy demand equations are estimated, although some existing empirical work could be interpreted as being consistent with our new specifications. Although information on energy efficiency may not be directly observed, we outline various ways that this energy efficiency can be modelled, such as by including exogenous trends and/or including its possible dependence on past energy prices. One simple version of our new approach is illustrated using an empirical example that involves estimation of an aggregate energy demand function for the UK with data over the period $1960-2011$.

We argued at the outset that our new approach has the potential for re-examining, and providing insights into, a number of issues in energy economics that have previously been approached in a somewhat unsatisfactory, and in some cases potentially misleading, ad hoc fashion. We discuss three possibilities here, although there are potentially many more. First, there is literature that argues how energy efficiency is dependent on, among other factors, past energy prices (see, for example, Gillingham et al., 2009). Our model, with its explicit inclusion of energy efficiency, justifies incorporation of various factors such as these directly in the energy demand equations, so that the role and relative importance of such factors can be ascertained empirically. Second, there is an extensive literature on the existence of asymmetric demand responses to energy price changes (see, for example, Gately and Huntington, 2002). Interestingly, the justification for the typical approach that is used usually entails an argument about how, as energy prices rise, energy-saving investments are made, and these are not undone should energy prices fall. But this is just an argument about how energy price rises induce increased energy efficiency (more energy services are provided with less energy - see, for example, Griffin and Schulman, 2005), which is clearly an issue that can be examined in our new model formulation where energy efficiency is explicitly included 
in the energy demand equations. Finally, a third issue that can perhaps be more appropriately addressed in our model concerns the empirical measurement of rebound effects in energy economics. This concept refers to the observation that with increased energy efficiency for various products, the savings in energy consumption that products embodying this higher level of energy efficiency are expected to elicit is typically, or at least frequently, not observed. These effects are often estimated in what might be regarded as a somewhat contrived way, using price elasticities obtained from energy demand equations (see, for example, Sorrell and Dimitropoulos, 2008). Yet rebound effects refer to the effect on demand for energy services of a change in the efficiency with which those services are provided (see, for example Sorrell, 2009). Thus, they are likely better examined in a model, such as the one introduced here, that explicitly accounts for demand for these services, and in such a setting their relationship to price elasticities obtained using typical energy demand equations might be better ascertained. 


\section{Acknowledgements}

This paper is partially based on earlier work under a different title that was presented and discussed at: the International Association for Energy Economics (IAEE) international conference in Stockholm, the Empirical Methods in Energy Economics (EMEE) workshop in Dallas, the Econometric Society Australasian Meetings (ESAM) in Melbourne, the Sustainable Development of Energy, Water and Environment Systems (SDEWES) conference in Dubrovnik, and the Canadian Resource and Environmental Economics Study Group conference in Vancouver. We are grateful for the many comments we received at these presentations that led to the redevelopment of this paper. We also thank, without implicating, Natural Resources Canada for initial funding support provided through the Canadian Building Energy End-Use Data and Analysis Centre (CBEEDAC). 


\section{References}

Adeyemi, O., D. C. Broadstock, M. Chitnis, L. C. Hunt, and G. Judge (2010), “Asymmetric price responses and the underlying energy demand trend: Are they substitutes or complements? Evidence from modelling OECD aggregate energy demand”, Energy Economics, 32(5), 1157-1164.

Adofo, Y. O., Evans, J., and L. C. Hunt (2013) "How sensitive to time period sampling is the asymmetric price response specification in energy demand modelling?", Energy Economics, 40, 90-109.

Baade, P. (1981) International energy evaluation system: international energy prices: 19551980. Information Administration, US Department of Energy Report, SR/ STID/8121, Washington, DC, USA.

Beenstock, M. and P. Willcocks (1981) "Energy consumption and economic activity in industrialized countries: The dynamic aggregate time series relationship”, Energy Economics, 3(4), 225-232.

Beenstock, M. and P. Willcocks (1983) "Energy and economic activity: a reply to Kouris", Energy Economics, 5(3), 212-212.

Bentzen, J. and T. Engsted (1993) "Short- and long-run elasticities in energy demand: A cointegration approach", Energy Economics, 15(1), 9-16.

Buse, A. (1994). "Evaluating the Linearized Almost Ideal Demand System", American Journal of Agricultural Economics, 76(4): 781-793.

Deaton, A., and J. Muellbauer (1980). “The Almost Ideal Demand System”, American Economic Review, 70(3): 312-326.

Dimitropoulos, J., L. C. Hunt, and G. Judge (2005) "Estimating underlying energy demand trends using UK annual data", Applied Economics Letters, 12(4), 239-244.

Doornik, J. A., and D. F. Hendry (2007) Empirical Econometric Modelling - PcGive 12, Econometric Software, Timberlake Consultants.

DUKES (n.d.) Digest of UK energy statistics, Department of Energy \& Climate Change, UK available at www.gov.uk/government/collections/digest-of-uk-energy-statistics-dukes.

Filippini, M. and L. C. Hunt (2011) "Energy demand and energy efficiency in the OECD countries: a stochastic demand frontier approach"', The Energy Journal, 32(2), 59-80. 
Fouquet, R., and P. J. G. Pearson (2012), “The Long Run Demand for Lighting: Elasticities and Rebound Effects in Different Phases of Economic Development", Economics of Energy \& Environmental Policy, 1(1): 83-100.

Gately, D., and H. G. Huntington (2002), "The Asymmetric Effects of Changes in Price and Income on Energy and Oil Demand", The Energy Journal, 23(1): 19-55.

Gillingham, K., R. G. Newell, and K. Palmer (2009), "Energy Efficiency Economics and Policy", Annual Review of Resource Economics, 1, 597-620.

Goerlich, R. and F. Wirl (2012), "Interdependencies between Transport Fuel Demand, Efficiency and Quality: An Application to Austria”, Energy Policy, 41, 47-58.

Griffin, J. M. and C. T. Schulman (2005), "Price Asymmetry in Energy Demand Models: A Proxy for Energy-Saving Technical Change?”, The Energy Journal, 26(2): 1-21.

Haas, R., N. Nakicenovic, and A. Ajanovic (2008), “Towards Sustainability of Energy Systems: A Primer on How to Apply the Concept of Energy Services to Identify Necessary Trends and Policies", Energy Policy, 36(11): 4012-4021.

Haas, R., and L. Schipper (1998), "Residential Energy Demand in OECD Countries and the Role of Irreversible Efficiency Improvements”, Energy Economics 20(4): 421-442.

Harvey, A. C. (1997), “Trends, Cycles and Autoregressions”, Economic Journal, 107(440): 192-201.

Howarth, R. B. (1997), “Energy Efficiency and Economic Growth”, Contemporary Economic Policy, 15: 1-9.

Hunt, L. C., G. Judge, and Y. Ninomiya (2003a), "Underlying trends and seasonality in UK energy demand: a sectoral analysis", Energy Economics, 25(1), 93-118.

Hunt, L. C., G. Judge, and Y. Ninomiya (2003b), "Modelling Underlying Energy Demand Trends", Chapter 9 in L.C. Hunt (ed) Energy in Competitive Markets: Essays in Honour of Colin Robinson, Edward Elgar, UK: 140-174.

Huntington, H. G. (2010), "Short- and Long-Run Adjustments in U.S. Petroleum Consumption”, Energy Economics, 32: 63-72.

IEA (2013a), Energy Balances of OECD Countries (Edition: 2013), International Energy Agency. Mimas, University of Manchester. DOI: http://dx.doi.org/10.5257/iea/ebo/2013. 
IEA (2013b), Energy Prices and Taxes (Edition 2013, Quarter 2), International Energy Agency. Mimas, University of Manchester. DOI: http://dx.doi.org/10.5257/iea/ept/2013q2.

Koopman, S. J., A. C. Harvey, J. A. Doornik, and N. Shephard (2007), Structural Time Series Analyser and Modeller and Predictor - STAMP 8, Econometric Software, Timberlake Consultants.

Kouris, G. (1983), “Energy Consumption and Economic Activity in Industrialized Economics: A Note”, Energy Economics, 5 (3), 207-212.

Prosser, R. D. (1985), "Demand elasticities in OECD: dynamic aspects”, Energy Economics, 7 (1), 9-12.

Ryan, D. L., and A. Plourde (2002), "Smaller and Smaller? The Price Responsiveness of Non-Transport Oil Demand", Quarterly Review of Economics and Finance, 42, 285317.

Ryan, D. L. (2014), “Deriving Useful Policy Implications from Findings of Asymmetric Energy Demand Responses to Price Changes: Using an Alternative Functional Form”, mimeo.

Schleich, J., B. Mills, and E. Dütschke (2014), “A Brighter Future? Quantifying the Rebound Effect in Energy Efficient Lighting”, Energy Policy, in press.

Sorrell, S. (2009), "The rebound effect: definition and measurement" Chapter 9 in Evans, J. and Hunt, L.C. (Eds) International Handbook on the Economics of Energy, Cheltenham, UK: Edward Elgar, UK, pp. 112-143.

Sorrell, S., and J. Dimitropoulos (2008), “The Rebound Effect: Microeconomic Definitions, Limitations and Extensions", Ecological Economics, 65(3): 636-649.

Walker, I. O., and F. Wirl (1993), "Irreversible Price-Induced Efficiency Improvements: Theory and Empirical Application to Road Transportation", The Energy Journal, 14(4): 183-205. 
Note:

This paper may not be quoted or reproduced without permission

Surrey Energy Economics Centre (SEEC) School of Economics

University of Surrey

Guildford

Surrey GU2 7XH 
SuRReY

ENERGY $_{\text {Net }}$

Economics

Discussion PAPER

$\mathbf{S}_{\text {ERIES }}$

\title{
For further information about SEEC please go to:
}

\author{
www.seec.surrey.ac.uk
}

